\title{
Novel circulating microRNAs expression profile in colon cancer: a pilot study
}

\author{
Ya-nan Wang ${ }^{1,2}$, Zhao-hua Chen ${ }^{2}$ and Wei-chang Chen ${ }^{1 *}$
}

\begin{abstract}
Purpose: To identify the expression profile of novel microRNAs (miRNAs) in colon cancer and evaluate their clinical applicability.

Methods: Differences in the expression of serum miRNAs in patients with colon cancer and healthy controls were identified using miRNA microarrays. Differentially expressed miRNAs were verified via real-time polymerase chain reaction (PCR) using sera from 50 patients with colon cancer and 44 healthy controls. These miRNAs were also verified in a double-blind validation experiment using sera from 30 patients with colon cancer, 30 patients with colonic polyps, and 30 healthy controls.

Results: Microarray hybridization revealed that 87 miRNAs were differentially expressed between the sera of patients with colon cancer and healthy controls. Among these miRNAs, 39 miRNAs were up-regulated, whereas 48 miRNAs were down-regulated. Verification of the expression of these miRNAs using real-time PCR revealed that the expression levels of miR-31, miR-141, miR-224-3p, miR-576-5p, and miR-4669 were significantly different between patients with colon cancer and healthy controls. Using these five miRNAs to construct a miRNA expression profile (or miRNA panel) will facilitate more effective diagnosis of colon cancer.
\end{abstract}

Conclusion: Clinical analysis of miR-31, miR-141, miR-224-3p, miR-576-5p, and miR-4669 expression in patients with colon cancer may facilitate the diagnosis of colon cancer.

Keywords: Colon cancer, MicroRNA-gene microarray, Molecular marker expression profile, Genetic diagnosis

\section{Background}

Colorectal cancer (CRC) is the fifth largest prevalent cancer in China. Since 2002, the incidence of CRC has increased from 16.4 to 34.3 per $10^{5}$ persons. The development of a positive and effective preventive measure is a major public health concern [1]. Additionally, early diagnosis of cancer in the clinical setting is particularly important [2]. As a new detection technology, genetic diagnosis has very wide application potential in tumor identification, optimization of treatment plan, improving patient prognosis, and tumor monitoring [3]. The expression profile of circulating molecular marker microRNAs (miRNAs) is an important component in tumor identification and genetic diagnosis [4]. miRNAs are

\footnotetext{
*Correspondence: weichangchen@126.com

1 The First Affiliated Hospital of Soochow University, Shizi Street \#188,

Suzhou 215006, Jiangsu, People's Republic of China

Full list of author information is available at the end of the article
}

non-coding, single-stranded RNAs that are 19-24 nucleotides in length. They are highly conserved, encoded by the host, and widely found in plants and animals. Since the discovery of the first miRNA let4 in Caenorhabditis elegans by Lee et al. [5] in 1993, there were 17,000 miRNA sequences and 15,000 miRNA loci belonging to 140 species in the miRbase as of 2011 [6].

Recent evidence has indicated that miRNAs are involved in various cancers [7]. Alterations of miRNA expression has been observed in many human tumors, including colon cancer [8], and these miRNAs are potential molecular markers for the diagnosis of colon cancer. For example, miR-155 was found to promote cancer cell proliferation, migration, invasion, drug resistance, and poor prognosis [9]. The miR-21 can increase proliferation of cancer cells as well as the clinical stage and recurrence rate, and reduce the apoptosis of tumor cells and survival duration of patients [10]. Members of the 
miR-17-92 family, can increase proliferation of tumor cells by affecting their cell cycle [11]. Moreover, as miR17-92 is relatively more sensitive, specific, and accurate [based on the area under the receiver operating characteristic (ROC) curve], it could be used as a marker for tumor identification, prognosis evaluation, and recurrence monitoring [12-18]. The potential use of miR17-92 as a marker sets a new path for the development of microRNA-derived molecular medicine for colon cancer. However, some miRNAs are lowly expressed in colon cancer. For instance, miRNA-145 could inhibit tumor metastasis and invasion, and hence may serve as a marker for early diagnosis of colon cancer $[19,20]$. High expression of the Lethal-7 family could inhibit the proliferation of cancer cells and tumor signal pathways to reduce the invasiveness of colon cancer that leads to poor prognosis, and improve the survival duration and progression-free survival time [21]. However, current studies are mostly focused on single miRNA targets for the diagnosis of colon cancer, and the accuracy and efficiency of such studies are low. Following the progress in miRNA research in recent years, the miRNA microarray detection system is thus developed. In this study, miRNA microarrays were used to detect the differential expression of various miRNAs in the sera of colon cancer patients and healthy controls. Real-time PCR was used to evaluate the differentially expressed miRNAs in colon cancer to identify their expression profile in the sera of colon cancer patients. The expression profiles of these miRNAs are of great clinical significance in the identification of colon cancer, the monitoring of tumor development, and evaluation of treatment plans, the prognosis of colon cancer patients, and their recurrence state.

\section{Methods}

\section{Patients}

Three serum samples from hospitalized patients with colon cancer (1 man and 2 women) at the Suzhou Municipal Hospital were used for microarray analysis. At the time of sample collection, none of the patients had undergone surgical treatment, radiotherapy, or chemotherapy. Diagnosis was made by pathological examination, and the histopathological types of the tumors were evaluated based on the pathological stages defined by the World Health Organization (WHO). Three serum samples from healthy controls were collected from patients undergoing physical examinations at the hospital.

For verification of miRNA expression by polymerase chain reaction (PCR), 50 serum samples were collected from patients ( 25 men and 25 women) with colon cancer at Suzhou Municipal Hospital. At the time of sample collection, the patients had not undergone surgical treatment, radiotherapy, or chemotherapy. Diagnosis was made by pathological examination, and the histopathological types of the tumors were evaluated based on the pathological stages defined by the WHO. Forty-four serum samples from healthy controls were collected from patients undergoing physical examination at the hospital. For the double-blind validation of miRNAs, 30 serum samples from hospitalized patients with colon cancer, 30 serum samples from patients with colon polyps, and 30 serum samples from healthy controls were collected from Suzhou Municipal Hospital. This study was approved by the hospital medical ethics committee, and informed consent was obtained from all patients.

\section{Sample collection}

Serum samples were collected from patients with colon cancer, patients with colon polyps prior to surgery, and healthy volunteers during physical examinations. Fasting venous blood $(5 \mathrm{~mL})$ was collected using disposable Vacutainer blood collection tubes. The blood was centrifuged at $3000 \mathrm{~g}$ for $5 \mathrm{~min}$ to separate the serum from the blood. The serum $(1 \mathrm{~mL})$ was preserved at $-80{ }^{\circ} \mathrm{C}$ after centrifugation.

\section{Microarray analysis}

miRNAme microarrays (miRNA UniTag ${ }^{\mathrm{TM}}$ ) were used to test the sera of three patients with colon cancer and three healthy controls. The samples were sent to Suzhou Institute of Nano-tech and Nano-bionics (SINANO) of the Chinese Academy of Sciences (CAS) for detection using the miRNA UniTag microarrays (i.e., unlabeled miRNA microarray analysis) [22]. After microarray hybridization, the data were analyzed. Differentially expressed miRNAs in patients with colon cancer compared with healthy controls were identified as those showing changes in expression of at least 1.5 -fold with $P<0.05$.

\section{Real-time PCR analysis}

For real-time PCR verification of miRNA expression, RNA was extracted from the serum samples. Serum $(250 \mu \mathrm{L}$ ) was added to $750 \mu \mathrm{L}$ TRIzol (Beijing Tiangen Biotech Co., Ltd.) in a $2 \mathrm{~mL}$ centrifuge tube, which was then vortexed to ensure complete mixing. RNA extraction was carried out according to the manufacturer's instructions. The absorbance ratio (A260/280) of total RNA, which was between 1.8 and 2.2, was determined using an ultraviolet (UV) spectrophotometer. The $3^{\prime}$ ends of the miRNAs were modified to have a poly(A) tail, and the miRNAs were reverse transcribed using an miRcute miRNA cDNA First-Strand Synthesis kit (Beijing Tiangen Biotech Co., Ltd.). Real-time fluorescence quantitative PCR was performed using an miRcute miRNA Fluorescence Quantitative Detection kit (Tiangen Biotech Co., Ltd.). Each reaction $(20 \mu \mathrm{L})$ included 
$10 \mu \mathrm{L}$ of $2 \times$ miRcute miRNA Premix (containing SYBR and ROX), $0.4 \mu \mathrm{L}$ of $10 \mu \mathrm{M}$ upstream and downstream primers, $2 \mu \mathrm{L}$ first-strand cDNA, $1.6 \mu \mathrm{L}$ of $50 \times$ ROX

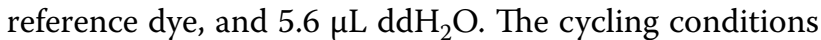
were as follows: predenaturation at $94{ }^{\circ} \mathrm{C}$ for $2 \mathrm{~min}$, followed by 43 cycles of $94{ }^{\circ} \mathrm{C}$ for $20 \mathrm{~s}$ and $60{ }^{\circ} \mathrm{C}$ for $34 \mathrm{~s}$. The expression of miR-16 was used as an internal Ref. [23] for normalization of target gene expression. Triplicate reactions were carried out for each target gene. Expression was calculated using the formula $2^{-\Delta \Delta C_{\mathrm{t}}}$ [24]. Amplified products of the fluorescence quantitative PCR $(10 \mu \mathrm{L})$ were electrophoresed on $30 \mathrm{~g} / \mathrm{Lagarose}$ gels, and gels were imaged using a Bio-Rad Gel Doc system (Broad Import \& Export Trading Co., Ltd. USA).

\section{Statistical analysis}

SPSS 17.0 (USA) was used for statistical analysis. The one-sample Kolmogorov-Smirnov test was used to evaluate the normal distribution of the data. Data that were normally distributed were evaluated using two-sample $t$ tests. One-way analysis of variance (ANOVA) was used to compare multiple groups of data, and SNK-q tests were used to compare two groups. Differences with $P<0.05$ were considered statistically significant.

\section{Results}

\section{Patient demographics}

The clinicopathological data for the patients are presented in Tables 1 and 2.

\section{Microarray analysis of miRNA expression profiles in serum from patients with colon cancer}

A total of 87 miRNAs were differentially expressed in the sera of patients with colon cancer compared with that in healthy controls. Among these, 39 miRNAs were up-regulated, and 48 miRNAs were down-regulated. The heat map of the 87 differentially expressed miRNAs is shown in Fig. 1, and the differentially expressed miRNAs are listed in Table 3.

\section{Verification of the differential expression of miRNAs using} PCR

Twelve of the 87 differentially expressed miRNAs identified from microarrays have been shown to be associated with cellular differentiation and metastasis in colon
Table 2 Clinical data of patients with colon cancer (for verification)

\begin{tabular}{lc}
\hline Parameter & Number \\
\hline Age & \\
$<60$ & 18 \\
$60-70$ & 19 \\
$>70$ & 13 \\
Sex & \\
Male & 25 \\
Female & 25 \\
Tumor size (cm) & \\
d $\leq 4$ & 29 \\
d>4 & 21 \\
Differentiation & \\
High & 5 \\
Medium & 37 \\
Low & 8 \\
TNM & \\
I II & \\
III & 18 \\
IV & 24 \\
Lymphatic metastasis & 8 \\
Positive & \\
Negative & 28 \\
\hline
\end{tabular}

cancer [25]. Thus, the expression of these 12 miRNAs was verified using real-time PCR. From this analysis, we found that the expression levels of $m i R-31, m i R-141$, $m i R-224-3 p, m i R-576-5 p$, and $m i R-4669$ were significantly different in patients with colon cancer compared with that in healthy controls (Fig. 2).

In a double-blind validation, the differential expression of these five miRNAs in colon cancer was consistent with the results of microarray analysis. Thus, these five miRNAs were then used to form an miRNA expression profile (miR panel, as shown in Fig. 3).

\section{Analysis of the identified miRNAs as markers of colon cancer}

For ROC curve analysis, pathology reports from patients who provided CRC samples were used as an evaluation standard. The ROC curves for miRNA-based diagnosis of colon cancer were plotted (Figs. 4, 5, Tables 4, 5).

Table 1 Pathological parameters of three colon cancer serum samples for microarray

\begin{tabular}{|c|c|c|c|c|c|c|}
\hline Microarray serum sample & Age & Sex & Tumor size $(\mathrm{cm})$ & Differentiation & TNM & Lymphatic metastasis \\
\hline $1 \#$ & 84 & Female & 3 & Media & III & Positive \\
\hline $2 \#$ & 64 & Male & 3 & Low & $\|$ & Negative \\
\hline $3 \#$ & 58 & Female & 5 & Media & $\|$ & Negative \\
\hline
\end{tabular}




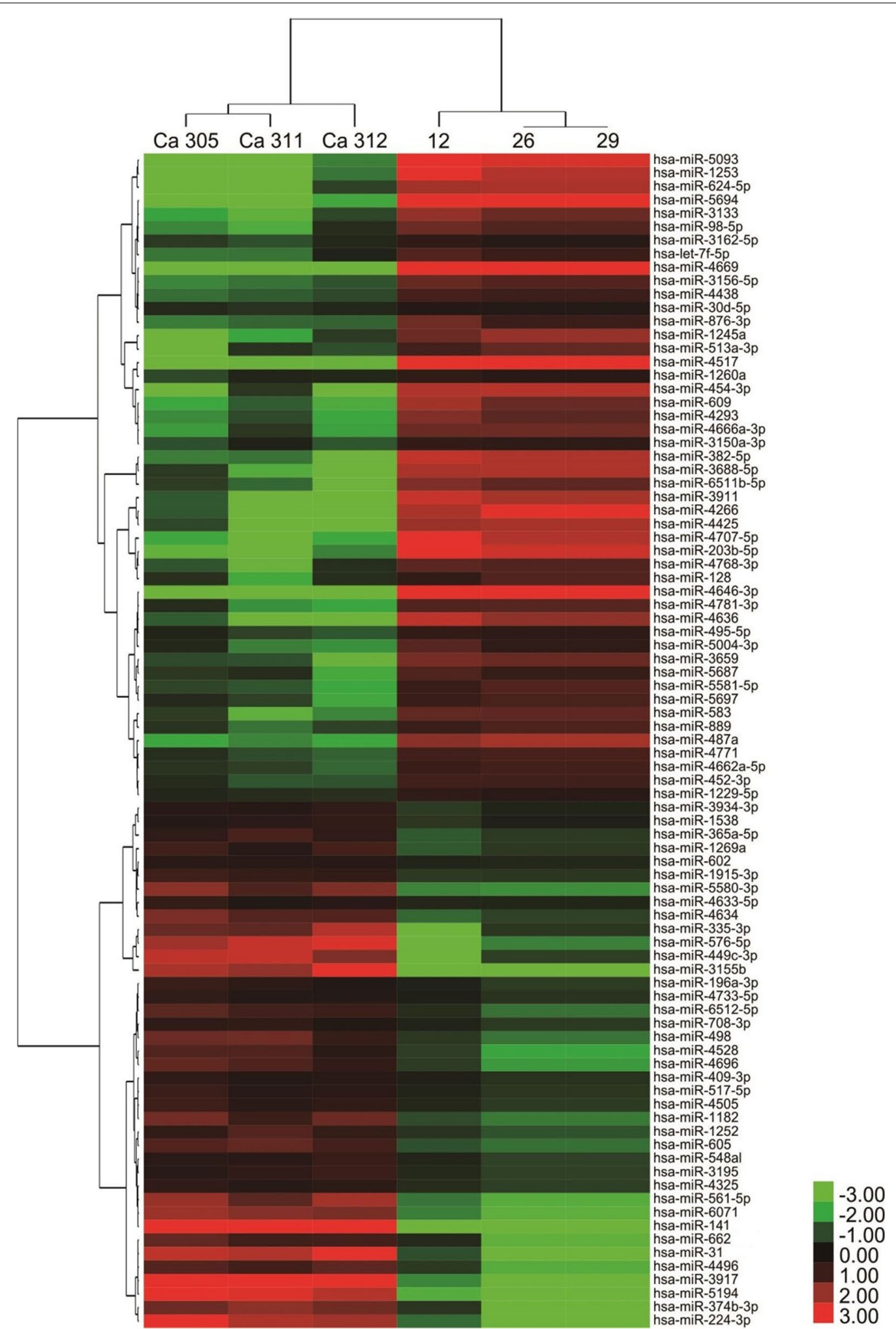

Fig. 1 Heat map of the miRNA microarray using serum samples from three patients with colon cancer and three healthy controls. Green denotes miRNAs with low expression, and red denotes miRNAs with high expression. The cut-off parameters were an expression change of at least 1.5 -fold and a $P$ value of less than 0.05 . Ca, CRC serum; $T$, healthy serum 
Table 3 Differentially expressed miRNAs in patients with colon cancer

\begin{tabular}{|c|c|c|}
\hline \multirow{2}{*}{$\begin{array}{l}\text { Up-regulated miRNAs } \\
\text { hsa-miR-602 }\end{array}$} & \multicolumn{2}{|c|}{ Down-regulated miRNAs } \\
\hline & hsa-miR-4669 & hsa-miR-4771 \\
\hline hsa-miR-4733-5p & hsa-miR-4646-3p & hsa-miR-4662a-5p \\
\hline hsa-miR-409-3p & hsa-miR-4517 & hsa-miR-452-3p \\
\hline hsa-miR-3934-3p & hsa-miR-5694 & hsa-miR-3150a-3p \\
\hline hsa-miR-1538 & hsa-miR-5093 & hsa-miR-495-5p \\
\hline hsa-miR-4633-5p & hsa-miR-1253 & hsa-miR-3162-5p \\
\hline hsa-miR-708-3p & hsa-miR-3911 & hsa-miR-1260a \\
\hline hsa-miR-4325 & hsa-miR-4707-5p & hsa-miR-30d-5p \\
\hline hsa-miR-196a-3p & hsa-miR-4266 & hsa-miR-1229-5p \\
\hline hsa-miR-517-5p & hsa-miR-203b-5p & \\
\hline hsa-miR-548al & hsa-miR-4425 & \\
\hline hsa-miR-3195 & hsa-miR-624-5p & \\
\hline hsa-miR-4505 & hsa-miR-4636 & \\
\hline hsa-miR-365a-5p & hsa-miR-454-3p & \\
\hline hsa-miR-1269a & hsa-miR-382-5p & \\
\hline hsa-miR-1915-3p & hsa-miR-3688-5p & \\
\hline hsa-miR-1252 & hsa-miR-487a & \\
\hline hsa-miR-4528 & hsa-miR-1245a & \\
\hline hsa-miR-6512-5p & hsa-miR-609 & \\
\hline hsa-miR-4696 & hsa-miR-3133 & \\
\hline hsa-miR-662 & hsa-miR-6511b-5p & \\
\hline hsa-miR-4496 & hsa-miR-583 & \\
\hline hsa-miR-605 & hsa-miR-4293 & \\
\hline hsa-miR-498 & hsa-miR-513a-3p & \\
\hline hsa-miR-1182 & hsa-miR-3659 & \\
\hline hsa-miR-4634 & hsa-miR-4666a-3p & \\
\hline hsa-miR-5580-3p & hsa-miR-3156-5p & \\
\hline hsa-miR-374b-3p & hsa-miR-876-3p & \\
\hline hsa-miR-335-3p & hsa-miR-98-5p & \\
\hline hsa-miR-6071 & hsa-miR-4781-3p & \\
\hline hsa-miR-561-5p & hsa-miR-5581-5p & \\
\hline hsa-miR-449c-3p & hsa-miR-4768-3p & \\
\hline hsa-miR-224-3p & hsa-miR-4438 & \\
\hline hsa-miR-31 & hsa-miR-5004-3p & \\
\hline hsa-miR-5194 & hsa-miR-5697 & \\
\hline hsa-miR-3917 & hsa-miR-5687 & \\
\hline hsa-miR-141 & hsa-let-7f-5p & \\
\hline hsa-miR-3155b & hsa-miR-128 & \\
\hline hsa-miR-576-5p & hsa-miR-889 & \\
\hline
\end{tabular}

From the ROC curves, the miRNA expression profiles (miR panel) obtained from the microarray and doubleblind validation tests showed area under the curve values of 0.995 and 0.964 , respectively. An miRNA expression profile consisting of the five miRNAs was more effective for predicting the diagnosis of colon cancer than that of a single miRNA.

\section{Analysis the expression of miRNAs with colon cancer different characteristics}

We also investigated the expression of miRNAs upon the various pathological parameters in colon cancer (see Fig. 6). There was significant difference of miR-31, miR-141, miR-224-3p, and miR-576-5p between welldifferentiated, moderate-differentiated, and poor-differentiated colon cancer $(P<0.05)$. It was obvious that the expression of above-mentioned RNAs was of increase with the differentiation decreased. In addition, miR31, miR-141, miR-224-3p, miR-576-5p, and miR-4669 showed notably different expression during different TNM stages $(P<0.05)$. Note that, miR-31, miR-141, miR224-3p, and miR-576-5p displayed high expression in lymphatic metastasis colon cancer, but miR-4669 exhibited enhancement on expression only in non-lymphatic metastasis colon cancer.

\section{Discussion}

CRC is one of the most common types of malignant tumors. The development of CRC involves the stages of hyperplasia, adenoma, and carcinogenesis, and this pathogenic process involves multiple genes. In recent years, the role of miRNAs in the development of CRC has become a major research focus. Current studies have indicated that miRNAs could function as oncogenes and tumor suppressors in CRC. Moreover, the development of miRNA microarrays has improved studies of the pathogenesis, early diagnosis, and prognosis of tumors owing to the advantages of high-throughput analysis and rapid detection of miRNA expression.

The UniTag microarray used in this study is an unlabeled miRNA microarray detection platform (including 2154 miRNAs, version 19.0) developed by the SINANO of CAS. The base stacking hybridization technology and the universal tag used by this platform can distinguish different miRNAs having single nucleotide differences. Moreover, this approach is particularly effective for ruling out inactive pri-miRNAs and pre-miRNAs that could yield cross-hybridized signals [22]. Our microarray screen revealed that 87 miRNAs were differentially expressed in the serum of patients with colon cancer compared with that of healthy controls. Among these miRNAs, 39 miRNAs were up-regulated, and $48 \mathrm{miR}$ NAs were down-regulated, with significant differences in the expression of greater than 1.5-fold. Furthermore, 


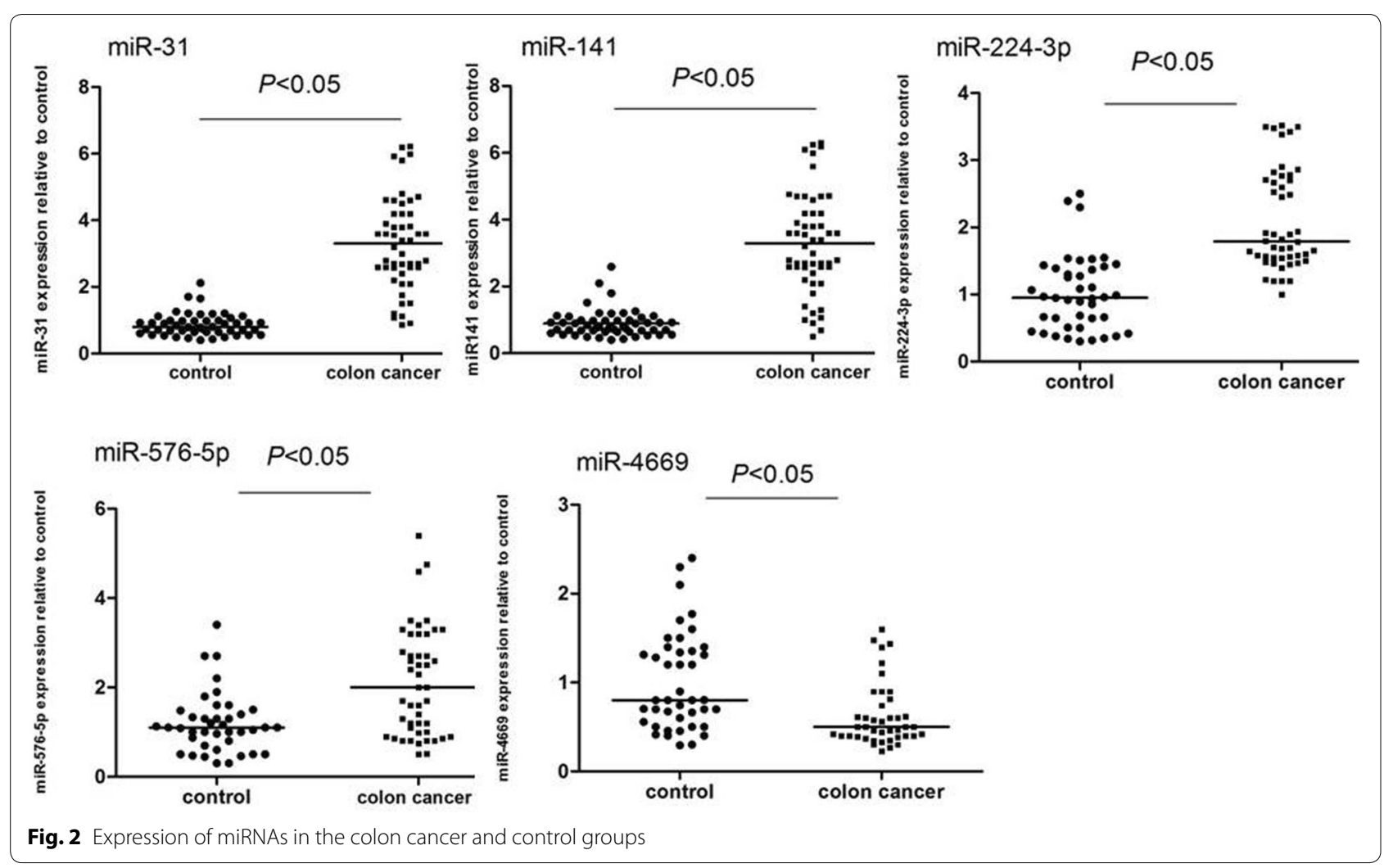

real-time PCR verified the changes in the expression of 5 of 12 miRNAs known to be related to cellular differentiation and metastasis of colon cancer [25]; specifically, miR-31, miR-141, miR-224-3p, miR-576-5p, and $m i R-4669$ were found to be differentially expressed in patients with colon cancer compared with that in healthy controls. Notably, $m i R-31$ and $m i R-141$ expression levels were three-fold higher in patients with colon cancer than in healthy controls. Recent studies have reported the close correlation between $m i R-31$ and CRC. For example, Yang et al. found that $m i R-31$ was highly expressed in CRC tissues and that miR-31 expression was significantly higher in metastasized CRC tissues than in nonmetastasized CRC tissues [26]. However, the specific role of miR-31 in CRC is unknown. Increased expression of $m i R-31$ in serum suggested that $m i R-31$ could serve as a potential tumor marker, and anticancer treatment targeting miR-31 could represent another important treatment option for CRC. miR-141 is evolutionarily conserved and shows high expression in epithelial tissues. miR-141 has been shown to be up-regulated in ovarian cancer, lung cancer, cholangiocarcinoma, prostate cancer, and CRC but down-regulated in gastric cancer, pancreatic cancer, liver cancer, and breast cancer, consistent with the ability of miRNAs to have oncogenic or tumor-suppressive roles indifferent of tumor types [27]. Additionally, miR141 expression has been shown to be higher in the blood of patients with late-stage CRC than that in the blood of patients with middle-stage CRC [28]. The results of this study indicated that miR-141 was highly expressed in the serum of patients with colon cancer and had an area under the ROC curve of 0.93 for the diagnosis of colon cancer, indicating relatively high diagnostic efficacy. Moreover, the expression levels of $m i R-576-5 p$ and $m i R$ 4669 were significantly associated with the differential diagnosis of colonic polyps and colon cancer. 


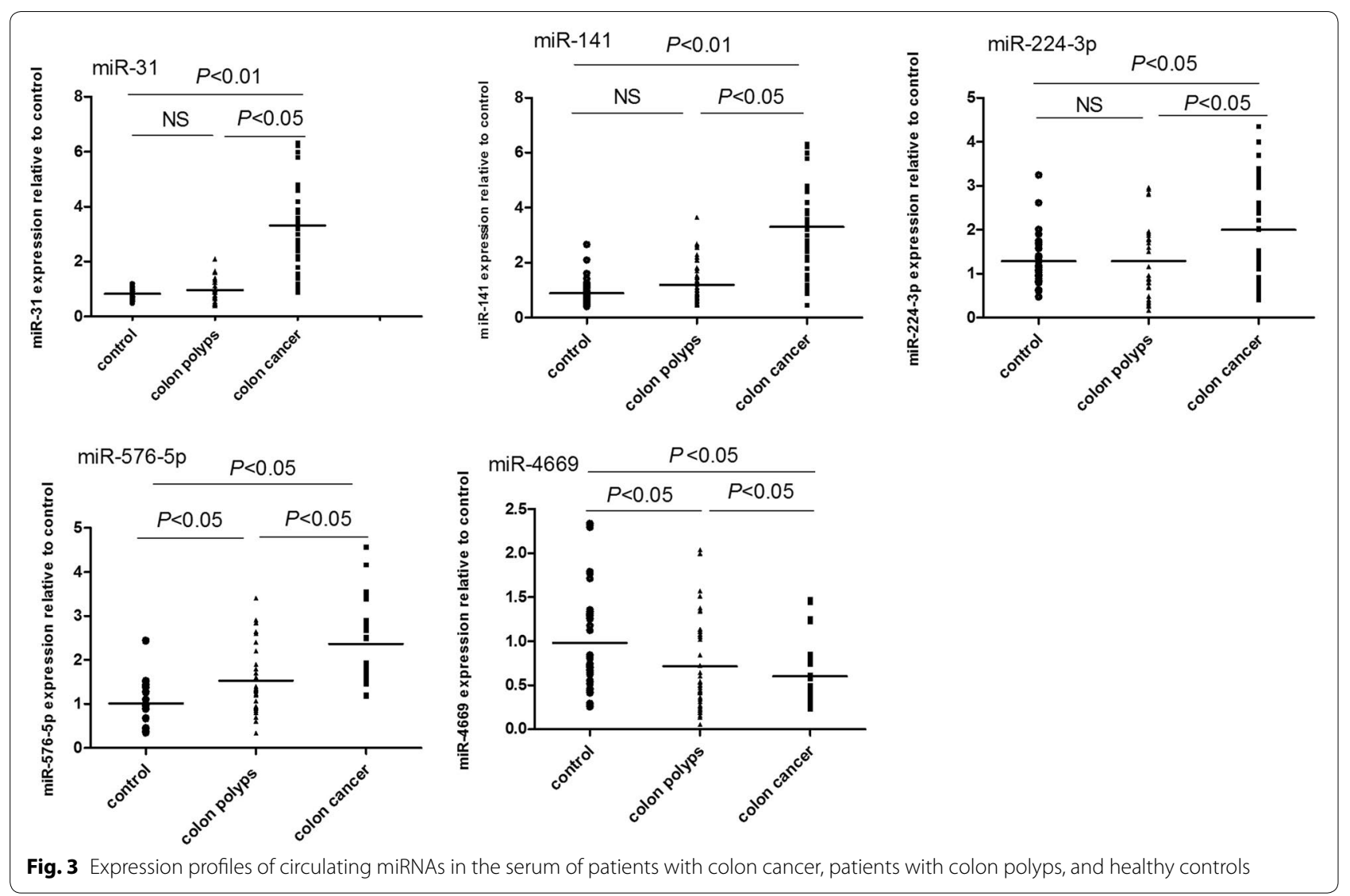

Importantly, the differential expression of these five miRNAs in patients with colon cancer was confirmed in a double-blind validation experiment, and these five miRNAs were then used to form an miRNA expression profile (miR panel). By plotting ROC curves, we found that the area under the curve values for the miR panel in the initial microarray screen and the double-blind validation experiment were 0.995 and 0.964 , respectively, demonstrating that the miR panel showed higher diagnostic accuracy for colon cancer than that of single miRNA expression. Because serum collection is convenient and simple, analysis of serum miRNA levels may be a suitable clinical tool for diagnosing and evaluating the prognosis of colon cancer. Indeed, the use of serum miRNA analysis may improve patient comfort during colon cancer evaluation and increase the sensitivity and specificity for the early diagnosis of colon cancer. According to the comparison of miRNAs among different pathologic parameters in colon cancer, we observed that the expression of miR-31, miR-141, miR-224-3p, miR576-5p was inversely correlated with the differentiation of cancer. miR-31, miR-141, miR-224-3p, miR-576-5p showed higher expression at TNM III and TNM IV than TNMI/II, miR-4669 was opposite. Furthermore, miR-31, 

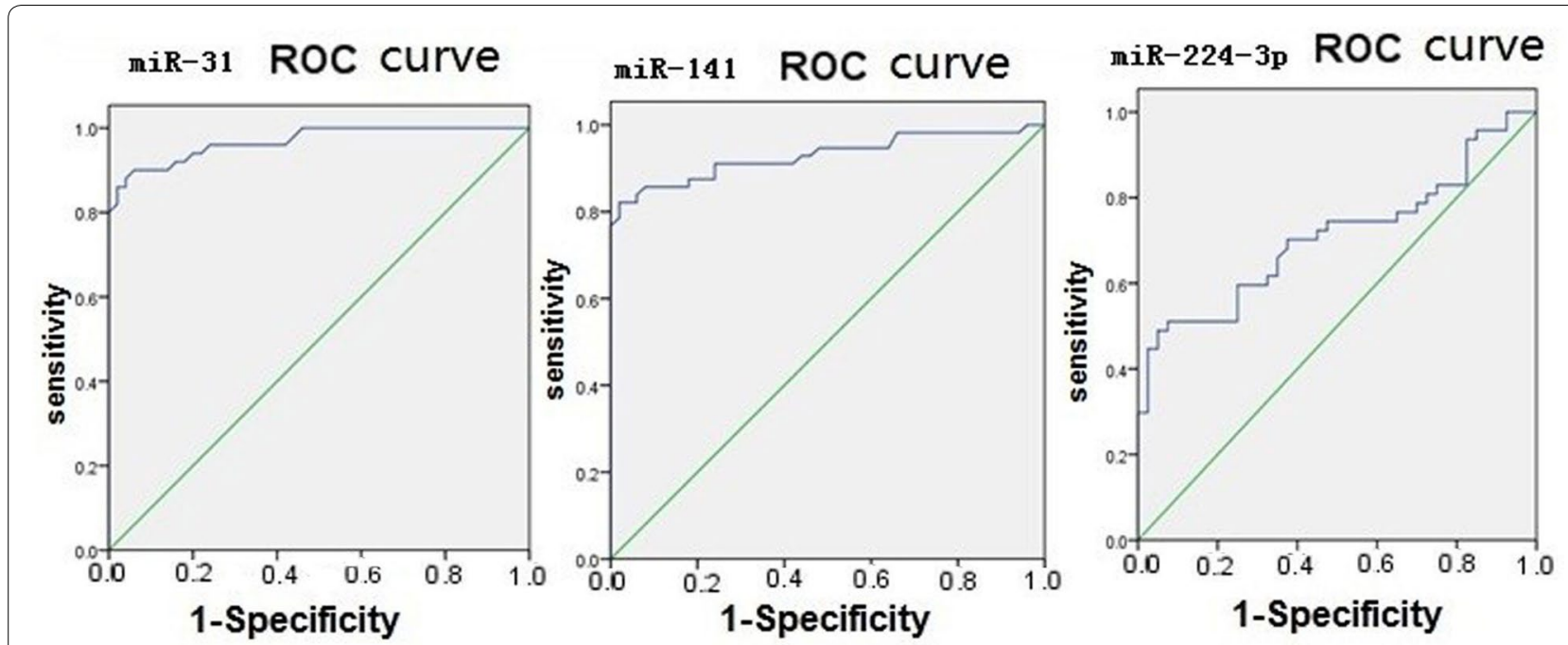

miR-576-5p ROC curve

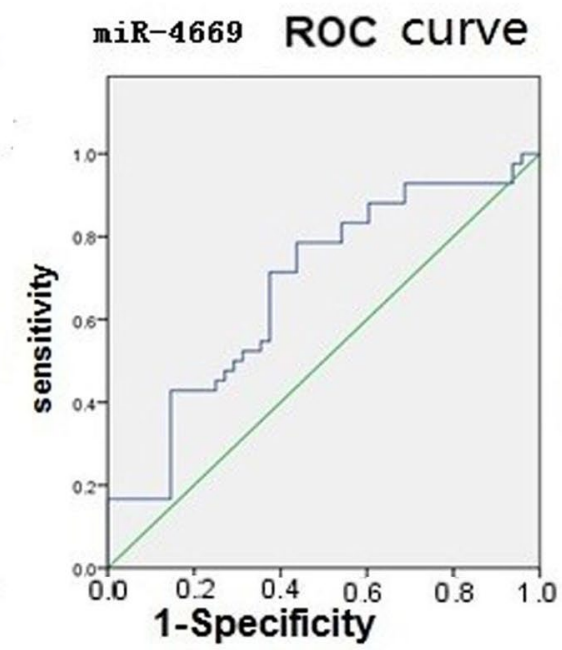

miR-panel ROC curve
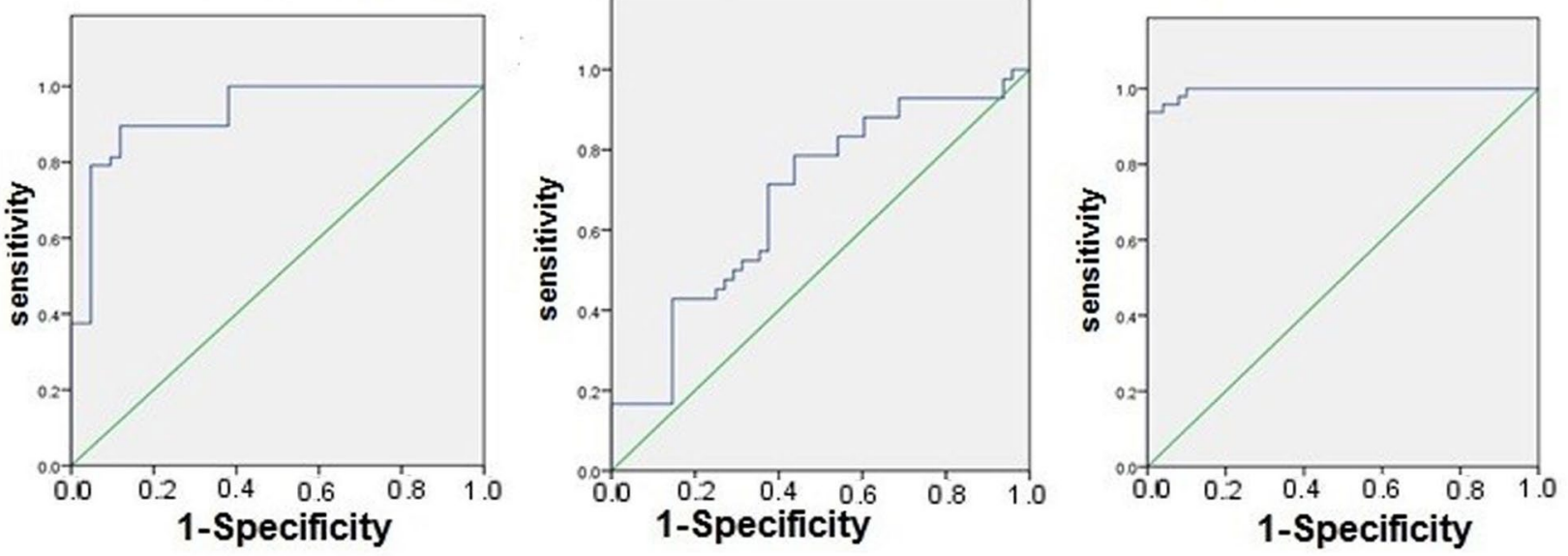

Fig. 4 ROC curves for miRNA-based diagnosis of colon cancer (microarrays)

miR-141, miR-224-3p, and miR-576-5p were commonly observed in lymphatic metastasis colon cancer, contrariwise, miR-4669 expressed highly only in non-lymphatic metastasis colon cancer. Therefore, the analysis of serum miRNA levels also can enhance prognosis evaluation, and prolong the survival of patients with colon cancer. Thus, after further studies to overcome the issues associated with high costs, miRNAme microarrays may be powerful tools for tumor diagnosis and treatment.

\section{Conclusion}

Our results suggested that analysis of the expression profiles of $m i R-31, m i R-141, m i R-224-3 p, m i R-576-5 p$, and $m i R-4669$ may facilitate the diagnosis of colon cancer. 

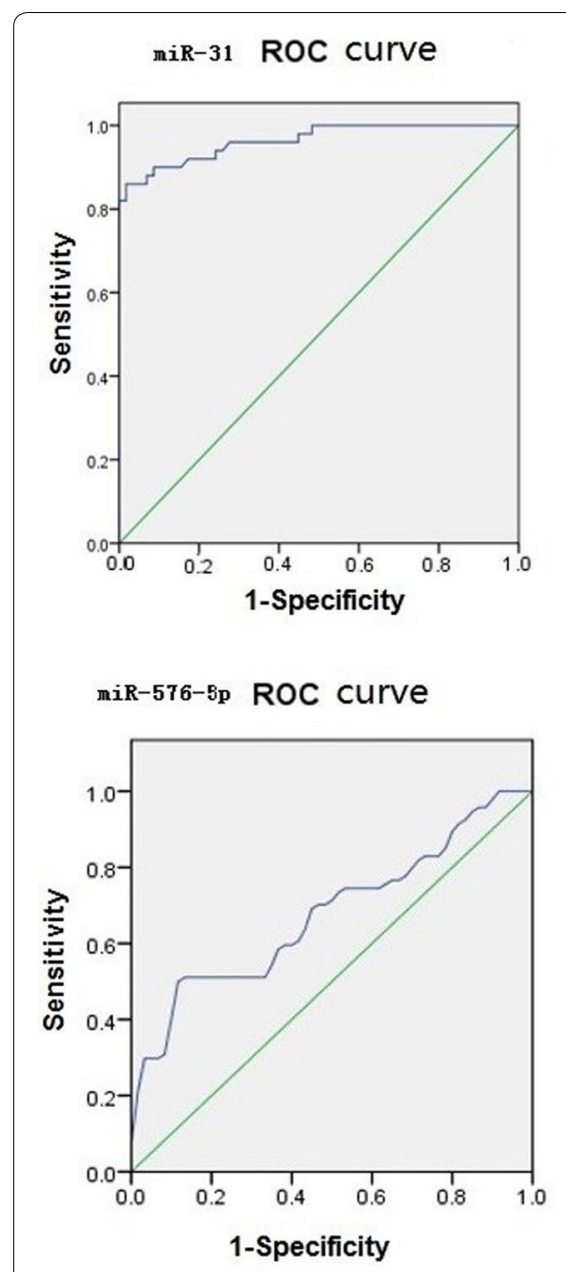
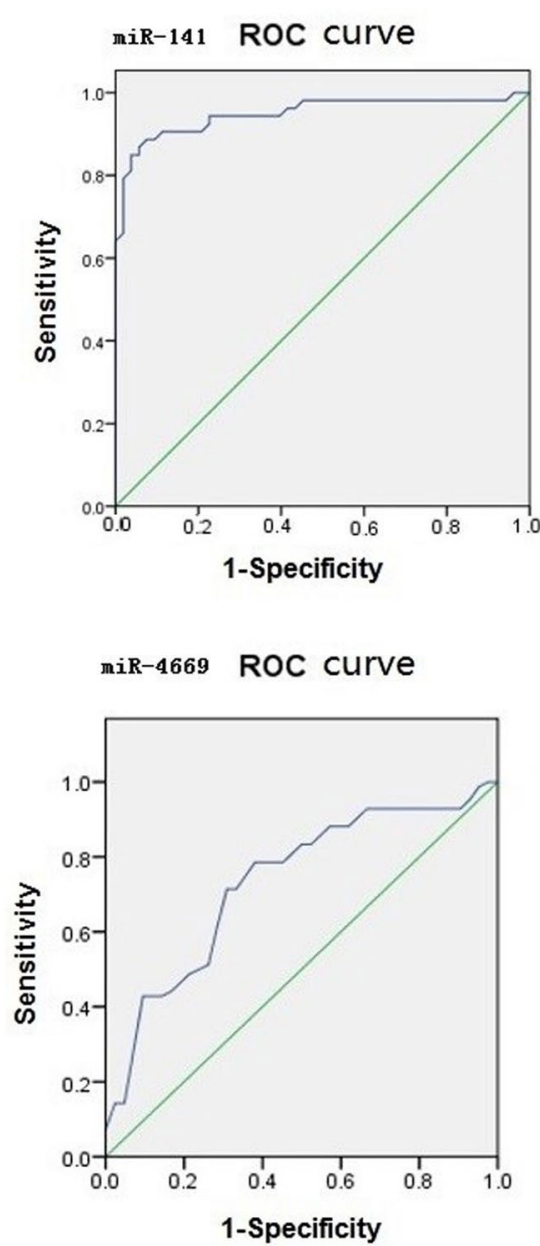

miR-224-3p ROC curve

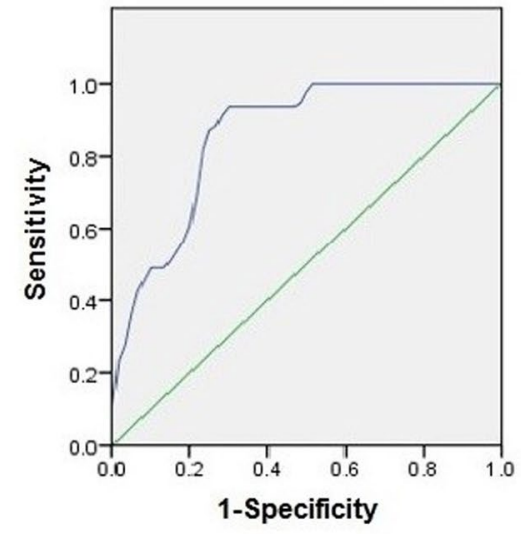

miR-panel ROC curve

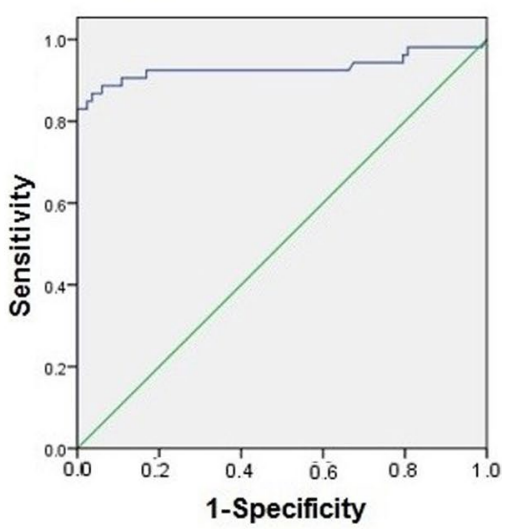

Fig. 5 ROC curves for miRNA-based diagnosis of colon cancer (double-blind validation test)

Table 4 Area under the ROC curve and asymptotic $95 \%$ confidence interval for miRNA-based diagnosis of colon cancer (microarrays)

\begin{tabular}{|c|c|c|c|c|c|}
\hline \multirow[t]{2}{*}{ miRNA } & \multirow[t]{2}{*}{ Area under the curve } & \multirow[t]{2}{*}{ Standard error } & \multirow[t]{2}{*}{ Asymptotic significance } & \multicolumn{2}{|c|}{$\begin{array}{l}\text { Asymptotic } 95 \% \text { confidence } \\
\text { interval }\end{array}$} \\
\hline & & & & Upper limit & Lower limit \\
\hline $\operatorname{miR}-31$ & 0.968 & 0.015 & 0.000 & 0.939 & 0.998 \\
\hline $\operatorname{miR}-141$ & 0.929 & 0.027 & 0.000 & 0.876 & 0.981 \\
\hline $\operatorname{miR}-224-3 p$ & 0.709 & 0.056 & 0.001 & 0.599 & 0.818 \\
\hline $\operatorname{miR}-576-5 p$ & 0.927 & 0.026 & 0.000 & 0.874 & 0.982 \\
\hline $\operatorname{miR}-4669$ & 0.678 & 0.057 & 0.004 & 0.576 & 0.790 \\
\hline miR expression profile & 0.995 & 0.004 & 0.000 & 0.999 & 1.000 \\
\hline
\end{tabular}


Table 5 Area under the ROC curve and asymptotic $95 \%$ confidence intervals for miRNA-based diagnosis of colon cancer in the double-blind validation test

\begin{tabular}{|c|c|c|c|c|c|}
\hline \multirow[t]{2}{*}{ miRNA } & \multirow[t]{2}{*}{ Area under the curve } & \multirow[t]{2}{*}{ Standard error } & \multirow[t]{2}{*}{ Asymptotic significance } & \multicolumn{2}{|c|}{$\begin{array}{l}\text { Asymptotic } 95 \% \text { confidence } \\
\text { interval }\end{array}$} \\
\hline & & & & Upper limit & Lower limit \\
\hline $\operatorname{miR}-31$ & 0.931 & 0.03 & 0.001 & 0.872 & 0.996 \\
\hline $\operatorname{miR}-141$ & 0.949 & 0.023 & 0.000 & 0.904 & 0.993 \\
\hline $\operatorname{miR}-224-3 p$ & 0.857 & 0.035 & 0.000 & 0.788 & 0.927 \\
\hline miR-576-5p & 0.678 & 0.054 & 0.002 & 0.573 & 0.783 \\
\hline miR-4669 & 0.734 & 0.055 & 0.000 & 0.625 & 0.842 \\
\hline miR panel & 0.964 & 0.030 & 0.000 & 0.872 & 0.99 \\
\hline
\end{tabular}

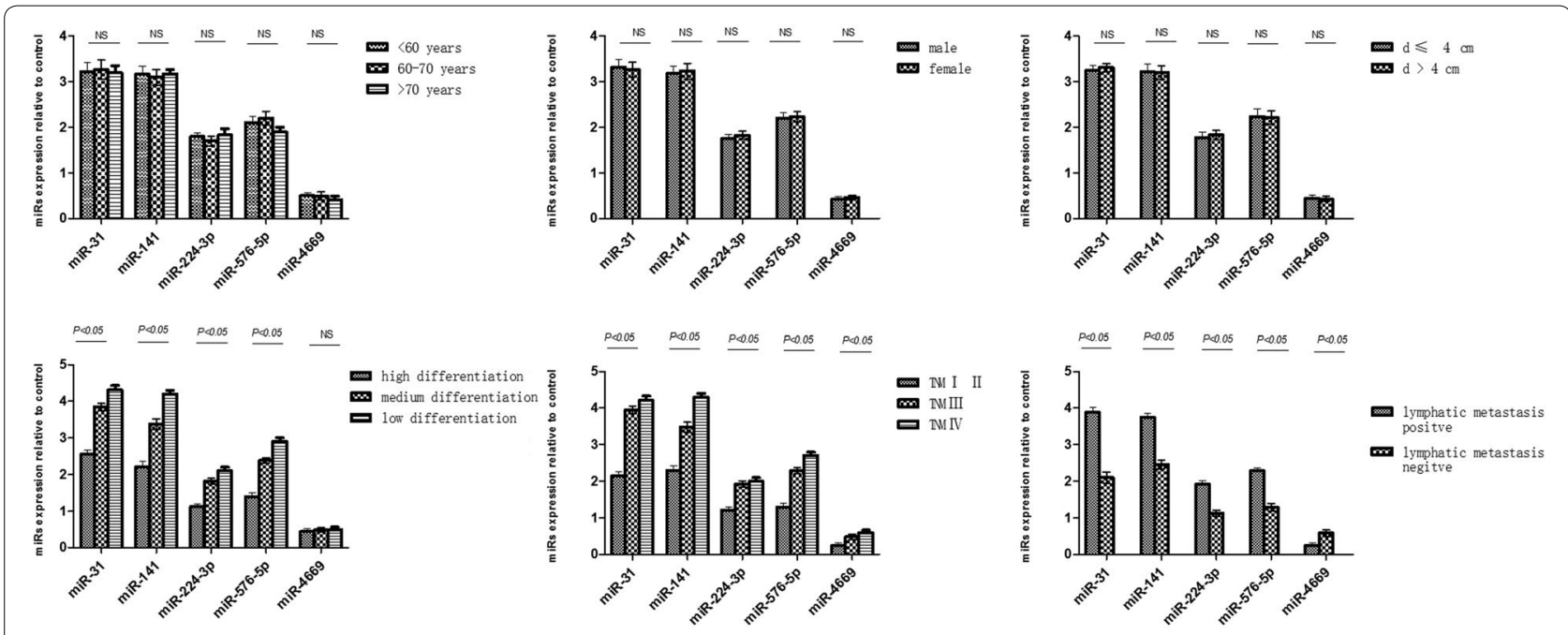

Fig. 6 Expression of miRNAs in colon cancer different characteristics

The expression profiles of these miRNAs may be potential important markers for clinical evaluation of colon cancer.

\section{Abbreviations}

CRC: colorectal cancer; PCR: polymerase chain reaction; miRNAs: microRNAs; ROC: receiver operating characteristic.

\section{Authors' contributions}

WYN, CZH, and CWC acquired data. WYN drafted the manuscript. CWC takes responsibility for the paper as a whole. All authors read and approved the final manuscript.

\section{Author details}

1 The First Affiliated Hospital of Soochow University, Shizi Street \#188, Suzhou 215006, Jiangsu, People's Republic of China. ${ }^{2}$ Suzhou Municipal Hospital, Suzhou Hospital Affiliated to Nanjing Medical University, Suzhou 215002, Jiangsu, People's Republic of China.

\section{Competing interests}

The authors declare that they have no competing interests.
Availability of data and materials

All the data are available in the manuscript or supporting information.

Consent for publication

All authors consented for the publication.

Ethics approval and consent to participate

This study was approved by the Ethical Committee of the Suzhou Municipal Hospital, and all participants have signed the informed consent.

\section{Funding}

This work was supported financially by Suzhou Science and Education ProjectYouth Science and Technology Foundation (NO.KJXW2014017).

\section{Publisher's Note}

Springer Nature remains neutral with regard to jurisdictional claims in published maps and institutional affiliations.

Received: 3 February 2017 Accepted: 17 November 2017

Published online: 29 November 2017 


\section{References}

1. Chen W, Zheng R, Zhang S, et al. Annual report on status of cancer in China. Chin J Cancer Res. 2014;26(1):48-58.

2. Kalmar A, Wichmann B, Galamb O, et al. Gene-expression analysis of a colorectal cancer-specific discriminatory transcript set on formalin-fixed paraffin-embedded (FFPE) tissue samples. Diagn Pathol. 2015;10(1):1-12.

3. Kahi CJ, Anderson JC, Rex DK. Screening and surveillance for colorectal cancer: state of the art. Gastrointest Endosc. 2013;77(3):335-50.

4. Ganepola GA, Nizin J, Rutledge JR, et al. Use of blood-based biomarkers for early diagnosis and surveillance of colorectal cancer. World J Gastrointest Oncol. 2014;6(4):83-97.

5. Lee RC, Feinbaum RL, Ambros V. The C. elegans hetero-chronic gene lin-4 encodes small RNAs with antisense complementarity to lin-14. Cell. 1993;75(5):843-54.

6. Kozomara A, Griffiths-Jones S. miRBase: integrating microRNA annotation and deep-sequencing data. Nucleic Acids Res. 2011;39:152-7.

7. Calin GA, Sevignani C, Dumitru CD, et al. Human microRNA genes are frequently located at fragile sites and genomic regions involved in cancers. Proc Natl Acad Sci USA. 2004;101(9):2999-3004.

8. Mazeh $\mathrm{H}$, Mizrahi I, llyayev N, et al. The diagnostic and prognostic role of microRNA in colorectal cancer-a comprehensive review. J Cancer. 2013:4(3):281-925.

9. Zhang GJ, Xiao HX, Tian HP, et al. Upregulation of colorectal cancer cells through the regulation of claudinl expression. Int J Mol Med. 2013;21(6):1375-80.

10. Yin J, Bai Z, Song J, et al. Differential expression of serum miR-126, miR141 and miR-21 as novel biomarkers for early detection of liver metastasis in colorectal cancer. Chin J Cancer Res. 2014;26(1):95.

11. Ke TW, Wei PL, Yeh KT, et al. MiR-92a promotes cell metastasis of colorectal cancer through PTEN-mediated P13K/AKT pathway. Ann Surg Oncol. 2015;22(8):2649-55.

12. Liu GH, Zhou ZG, Chen R, et al. Serum miR-21 and miR-92a as biomarkers in the diagnosis and prognosis of colorectal cancer. Tumour Biol. 2013;34(4):2175-81.

13. Knudsen KN, Nielsen BS, Lindebjerg J, et al. microRNA-17 is the most up-regulated member of the miR-17-92 cluster during early colon cancer evolution. PLoS ONE. 2015;10(10):e0140503.

14. Fang LL, Wang $X H$, Sun BF, et al. Expression, regulation and mechanism of action of the miR-17-92 cluster in tumor cells (review). Int J Mol Med. 2017 (Epub ahead of print)
15. Li J, Liu Y, Wang C, et al. Serum miRNA expression profile as a prognostic biomarker of stage II/III colorectal adenocarcinoma. Sci Rep. 2015;5:12921.

16. Yu G, Tang JQ, Tian ML, et al. Prognostic values of the miR-17-92 cluster and its paralogs in colon cancer. J Surg Oncol. 2012;106(3):232-7.

17. Liu F, Zhang F, Li X. Prognostic role of miR-17-92 family in human cancers: evaluation of multiple prognostic outcomes. Oncotarget. 2017;8(40):69125-38

18. Zhang $\mathrm{K}$, Zhang $\mathrm{L}$, Zhang $\mathrm{M}$, et al. Prognostic value of high-expression of miR-17-92 cluster in various tumors: evidence from a meta-analysis. Sci Rep. 2017;7(1):8375.

19. Ramzy I, Hasaballah M, Marzaban R, et al. Evaluation of microRNA-29a, 92a and 145 in colorectal carcinoma as candidate diagnostic markers: an Egyptian pilot study. Clin Res Hepatol Gastroenterol. 2015;39(4):508-51.

20. Yuan W, Sui C, Liu Q, et al. Up-regulation of microRNA-145 associates with lymph node matastasis in colorectal cancer. PloS ONE. 2014;9(7):e102017.

21. Wang J, Huang SK, Zhao M, et al. Identification of a circulating microRNA signature for colorectal cancer detection. PLOS ONE. 2014;9(4):e87451.

22. Chen YF, Yang CC, Kao SY, et al. MicroRNA-211 enhances the oncogenicity of carcinogen-induced oral carcinoma by repressing TCF12 and increasing antioxidant activity. Cancer Res. 2016;76(16):4872-86.

23. Huang $Z$, Huang $D, N i$, et al. Plasma microRNAs are promising novel biomarkers for early detection of colorectal cancer. Int J Cancer. 2010;127(1):118-26.

24. Schmittgen TD, Livak KJ. Analyzing real-time PCR data by the comparative Ct method. Nat Protoc. 2008;3(6):1101-8.

25. Mazeh Haggi, Mizrahi Ido, llyayev Nadia, et al. The diagnostic and prognostic role of microRNA in colorectal cancer-a comprehensive review. J Cancer. 2013:4(3):281-95.

26. Yang $\mathrm{MH}$, Jiang $\mathrm{Y}$, Chen $\mathrm{N}$, et al. Elevated microRNA-31 expression regulates colorectal cancer progression by repressing its target gene SATB2. PLOS ONE. 2013;8(12):e85353.

27. Gao Y, Feng B, Han S, et al. The roles of microRNA-141 in human cancers: from diagnosis to treatment. Cell Physiol Biochem. 2016;38(2):427-48.

28. Sun Y, Liu Y, Cogdell D, et al. Examining plasma microRNA markers for colorectal cancer at different stages. Oncotarget. 2016;7(10):11435-49.

\section{Submit your next manuscript to BioMed Central and we will help you at every step:}

- We accept pre-submission inquiries

- Our selector tool helps you to find the most relevant journal

- We provide round the clock customer support

- Convenient online submission

- Thorough peer review

- Inclusion in PubMed and all major indexing services

- Maximum visibility for your research

Submit your manuscript at www.biomedcentral.com/submit
BioMed Central 